\title{
Journal of Sports Medicine and Allied Health Sciences: Official Journal of the Ohio Athletic Trainers Association
}

Volume 6

Issue 3 JSMAHS Spring Issue 2021

Article 3

March 2021

\section{Lower Extremity Musculoskeletal Screening Tool Practices Among Athletic Trainers in Secondary School and Collegiate Settings}

\author{
Megan B. Fowler \\ Indiana State University, megan.brooke.fow@gmail.com \\ Elizabeth R. Neil \\ Temple University, beth.neil@temple.edu \\ Cameron J. Powden \\ University of Indianapolis, powdenc@uindy.edu
}

Follow this and additional works at: https://scholarworks.bgsu.edu/jsmahs

Part of the Biomechanics Commons, Exercise Science Commons, Motor Control Commons, Other Kinesiology Commons, Rehabilitation and Therapy Commons, Sports Medicine Commons, and the Sports Sciences Commons

How does access to this work benefit you? Let us know!

\section{Recommended Citation}

Fowler, Megan B.; Neil, Elizabeth R.; and Powden, Cameron J. (2021) "Lower Extremity Musculoskeletal Screening Tool Practices Among Athletic Trainers in Secondary School and Collegiate Settings," Journal of Sports Medicine and Allied Health Sciences: Official Journal of the Ohio Athletic Trainers Association: Vol. 6: Iss. 3, Article 3. DOI: https://doi.org/10.25035/jsmahs.06.03.03

Available at: https://scholarworks.bgsu.edu/jsmahs/vol6/iss3/3

This Article is brought to you for free and open access by the Journals at ScholarWorks@BGSU. It has been accepted for inclusion in Journal of Sports Medicine and Allied Health Sciences: Official Journal of the Ohio Athletic Trainers Association by an authorized editor of ScholarWorks@BGSU. 


\section{Lower Extremity Musculoskeletal Screening Tool Practices Among Athletic Trainers in Secondary School and Collegiate Settings}

\section{Cover Page Footnote}

Funding to complete the study was obtained from Indiana State University in the form of the Graduate Student Research Grant. 


\title{
Lower Extremity Musculoskeletal Screening Tool Practices Among Athletic Trainers in Secondary School and Collegiate Settings
}

\author{
Megan B. Fowler, DAT, LAT, ATC*; Elizabeth R. Neil, PhD, LAT, ATC\#; Cameron J. Powden, PhD, LAT, ATC $€$ \\ *Indiana State University, \#Temple University, ${ }^{€}$ University of Indianapolis
}

Purpose: Musculoskeletal (MSK) screening tools can allow athletic trainers (AT) to focus prevention efforts by providing patient risk information. The purpose of this study is to examine lower extremity MSK screening tool practices and perceptions of ATs in traditional settings. Methods: A cross-sectional online survey was distributed to 4,937 full- and part-time collegiate and secondary school ATs randomly selected by the NATA. MSK screening tools were grouped into 7 categories: Range of Motion (ROM), Strength, Balance, Drop and Jump Landing (D/J Land), Double- and Single-Leg Hopping (D/S Hop), Movement Quality (MQual), and Injury History (History). For each screening tool category, questions assessed MSK screening tool usage, the perceived effectiveness of MSK screening tools to provide relevant injury risk and return to play (RTP) information, and MSK screening tools effect on decisions to implement prevention programs. Results: A total of 372 participants (female $=215(48.4 \%)$, male $=152(34.2 \%)$, age $=35 \pm 10$ years, experience $=12 \pm 10$ years, secondary school $=194(52.2 \%)$, collegiate $=178(47.8 \%)$ ) completed the survey. Participants within our study indicated the used of the following screening tools categories in clinical practice: $\mathrm{ROM}=339(91.1 \%)$, Strength=342(91.9\%), Balance=238(64.0\%), D/J-Landing=134(36.0\%), D/S-Hopping=233(62.6\%), MQual=212(57.0\%), History=316(85.0\%), and None=18(4.8\%). Conclusions: ATs in traditional settings indicate that they primarily use ROM, Strength, and History screening tools to gather information concerning LE injury risk and RTP. Implementation of screening tools most frequently occurred post-injury. Lastly, it seemed that intervention prescriptions were consistent regardless of screening tool used, suggesting blanket interventions prescription. This may be due to participant perceptions that these tools are moderately effective at determining injury risk. Keywords: Prevention, Outcome Measures, Risk Assessment, Return to Sport

\section{INTRODUCTION}

Musculoskeletal (MSK) injuries are disabling in nature and alter the ability of an individual to participate in physical activity and activities of daily living (ADLs). ${ }^{1}$ Athletes have an increased risk of MSK injuries compared to those that participate in recreational physical activity, due to intense training sessions and the length of session that typically last longer than recreational activity. ${ }^{1}$ For example, lateral ankle sprains are considered one of the most common lower extremity injuries and most common injury in sport.1,2 In fact, lateral ankle sprains have an incidence rate of about 25,000 daily in the United States. $^{3}$ Once a lateral ankle sprain has been sustained, a myriad of mechanical and neuromuscular deficits occur that lead to an increased risk of recurrent of injury. ${ }^{2-6}$ This injury cycle leads to about $70 \%$ of individuals suffering from long-term disability, such as osteoarthritis and chronic joint inflammation.7,8 Effective prevention strategies are needed to reduce the incidence of MSK injury and subsequently halt the cycle of disability that can occur due to these injuries.

Prevention strategies of certified athletic trainers are implemented with the intention of reducing the inherent injury associated with sport. As such, substantial knowledge of both the activity as well as individual movement patterns is needed to develop effective injury prevention programs..$^{9}$ On average, athletic trainers report spending upwards of almost $50 \%$ of patient encounters on preventative measures. ${ }^{10}$ Some of these prevention strategies and programs are established based on unique individual needs, whereas other programs are based on sportspecific demands, such as using a team-based approach. ${ }^{11}$ What remains consistent is the lack of translation of knowledge of the benefits of prevention programs, and the successful implementation of these prevention programs within athletic training. 3,11,12 While prevention programs have been shown to reduce risk of injuries, these programs have limitations of their own, such as the time it takes to teach and 
implement corrective exercises to improve movement patterns. ${ }^{13}$ Within athletic training, lack of time is a consistent barrier, especially for those in traditional settings (college and secondary school), therefore, it seems logical to assume that athletic trainers should have a systematic way of determining specific preventative measures needed. ${ }^{13}$

Determining dysfunctional patterns of movement and need for preventative measures begins with a systematic way of screening patients. MSK screening tools serve to define areas of weakness or dysfunctional immobility and movements, such as identifying individuals that demonstrate highrisk movement patterns associated with anterior cruciate ligament tears. ${ }^{8}$ Using MSK screening tools to determine specific impairments related to risk of injury can help athletic trainers and other healthcare professionals involved in the injury prevention process establish the unique needs of each patient and focus resources.5,8,14,15 Some of the commonly investigated risk factors include range of motion, strength, movement patterns, biomechanics, motor control, and injury history.1,6,15,16 By establishing the specific impairments of the patient based on the feedback from MSK screening tools, preventative measures can be uniquely prescribed that aid to reduce the severity of risk factor the patient might possess. MSK screening tools can allow the athletic trainer to evaluate the dynamic movements outside of sport that reveal any weaknesses, dynamic postural instability, lack of neuromuscular control, and faulty motor firing patterns, to better determine unique needs of the individual to create more targeted prevention measures. ${ }^{15,17}$

There has been some research conducted concerning MSK screening tools in other settings of physically active populations, such as the military utilizing the 1-1-1 test, and normative values for specific screening tools. 16,18 What is lesser known, however, is the injury screening practices within traditional athletic training settings. Understanding the habits of screening patients for injury risk among athletic trainers in traditional settings holds the potential to reveal important information. Besides the actual screening tool habits, there is a lack of research that describes the perceptions regarding effectiveness and usefulness of lower extremity
(LE) MSK screening tools being used by athletic trainers. The purpose of this study is to investigate the screening tool practices of athletic trainers in traditional settings and their perceptions regarding the efficacy of MSK screening tools. We hypothesized that athletic trainers will indicate limited use of MSK tools with range of motion (ROM) and strength tools being most commonly used. Additionally, we hypothesized that the use of these screening tools will primarily occur postinjury. Finally, we hypothesized that athletic trainers will indicate perceptions of moderate effectiveness of these screening tools to identify injury risk and provide RTP information.

\section{METHODS}

\section{Research Design}

A cross-sectional survey was designed to investigate LE MSK screening tool practices of athletic trainers in traditional settings via an online questionnaire (Qualtrics $®$, Provo, UT). The university's institutional review board approved this study.

\section{Content Analysis and Pilot Testing}

The tool was drafted based on the expertise and creativity of the research team that aligned with the study goals. After creating a draft of the survey, the research team sent the survey to a panel of experts. A total of four experts composed the content analysis panel: two general injury prevention and MSK screening experts, one survey design expert, and one LE prevention expert. After the feedback from the content analysis panel was collected, alterations and corrections were made to the survey by the research team. The content analysis review was repeated until no more comments were given by the expert panel. The survey was then distributed to a pilot test group $(n=27)$ of practicing athletic trainers for content review and validity. Concluding the pilot test, alterations and corrections to the survey again were made once more before a final draft of the survey was completed. The data gained in the pilot testing were not used in the final analysis.

\section{Instrumentation}

The Qualtrics $®$ survey platform was used for this study. The questions regarding screening tools were divided into seven categories: range of motion (ROM), dynamic and static balance (Balance), strength (Strength), drop and/or jump 
landing (D/J Land), single- and double-leg hopping ( $S / D$ Hop), movement quality (MQual), and injury history (History). Within the survey, definitions of each screening tool category were provided as well as examples of common screening tools for that category (Table 1). Based on the selection of screening tool categories used by participants, the subsequent blocks of questions were randomized. The survey had four identical main sections within each category of screening tools: (1) implementation of LE MSK screening tool, (2) timing of implementation, (3) perceived effectiveness of screening tool, and (4) the resulting prevention/rehabilitation program (balance training, ROM program, bracing program, etc.) prescribed based on information gathered from the screening tool. The number of questions that each participated viewed varied depending on what categories of screening tools each participant selected.
For example, if a participant only selected that he/she used ROM screening tools in section one, he/she would only receive questions pertaining to $R O M$ in the following sections. The number of questions could range from 16 to 86 questions in total.

\section{Participants}

Participants were recruited through the National Athletic Trainers' Association survey platform. Members who were either registered as a full-time or part-time clinical athletic trainer in the traditional clinical practice settings (secondary school and collegiate settings) were included in the research study. Those that were full-time educators, split educator/clinician role, and that were practicing in non-traditional settings were excluded.

\begin{tabular}{|c|c|}
\hline Category & Definition \\
\hline Range of Motion & $\begin{array}{l}\text { These tools assess the passive and active range of motion of an individual, such as } \\
\text { goniometry and the straight leg raise. }\end{array}$ \\
\hline Strength & $\begin{array}{l}\text { These tools assess an individual's muscular strength, such as manual muscle testing, } \\
\text { one repetition maximum, and isometric assessment. }\end{array}$ \\
\hline Dynamic and Static Balance & $\begin{array}{l}\text { These tools assess an individual's ability to maintain postural control during tasks } \\
\text { such as quite single limb stance or during movement. Specific examples include the } \\
\text { Y-balance test and Star Excursion Balance Test. }\end{array}$ \\
\hline Drop and/or Jump Landing & $\begin{array}{l}\text { These tools assess an individual's functional ability to land from a drop or from a } \\
\text { jump, such as the Landing Error Scoring System or Tuck Jump Assessment. }\end{array}$ \\
\hline Single-Leg and/or Double-Leg Hopping & $\begin{array}{l}\text { These tools assess an individual's ability to make multiple jumps or hops in a row, on } \\
\text { either one or two legs, such as the triple hop for distance and crossover hop test. }\end{array}$ \\
\hline Movement Quality & $\begin{array}{l}\text { These tools assess an individual's quality and movement form during a specific task. } \\
\text { Examples of this type of screening tool include the Functional Movement Screen and } \\
\text { the Functional Capacity Screen. }\end{array}$ \\
\hline Injury History & $\begin{array}{l}\text { These tools assess an individual's history of musculoskeletal injuries and potential } \\
\text { current limitations in the individual's ability to participate in athletic events, such as } \\
\text { a pre-participation review or patient-reported outcome measures. }\end{array}$ \\
\hline
\end{tabular}

Table 1. Injury Screening Tool Category

Definitions

\section{Procedures}

An initial recruitment email was distributed to 4,937 athletic trainers matching the inclusion criteria, declaring the purpose of the research and requesting participation. Participants were given a four-week window to complete the survey and a reminder follow-up email was distributed after two and three weeks. Athletic trainers that met the inclusion criteria and who were willing to participate completed the survey through Qualtrics ${ }^{\circledR}$ online survey platform from a link provided in the recruitment email. 


\section{Data Analysis}

Data were analyzed using both SPSS (Version 25; IBM Corporation, Armonk, NY) and Microsoft Excel (2010, Microsoft Corporation, version 14.7.0). Data coding was done on Excel, then imported into SPSS. Data were analyzed descriptively using frequencies and counts in SPSS to examine trends. We compared categories of MSK screening tools usage overall, frequency of use at different times of the year, RTP perceived effectiveness of each MSK screening tool, and intervention prescription based on the MSK screening tool.

\section{RESULTS}

After those that chose not to give consent and those that did not work clinically in the traditional setting were removed, a total of 372 participants (215 female, 152 male, age $=35.4 \pm 10.36 \mathrm{yrs}$, experience $=12.0 \pm 9.7 \mathrm{yrs}$ ) completed the survey (response rate $=7.5 \%$, access rate $=8.6 \%$, completion rate $=95.8 \%$ ). Please see Table 2 for demographic information about the participants.

\begin{tabular}{|l|l|l|}
\hline & Frequency & Valid Percent \\
\hline Demographic data & 12.02 & NA \\
\hline $\begin{array}{l}\text { Years of clinical } \\
\text { Experience (average) }\end{array}$ & $\begin{array}{l}\text { years } \\
\text { (SD 9.69) }\end{array}$ & \\
\hline Male & 152 & $34.2 \%$ \\
\hline Female & 215 & $48.4 \%$ \\
\hline Prefer no to answer & 4 & $0.9 \%$ \\
\hline $\begin{array}{l}\text { Clinical } \\
\text { Practice Setting }\end{array}$ & & \\
\hline NJCAA & 18 & $4.1 \%$ \\
\hline NAIA & 11 & $2.5 \%$ \\
\hline NCAA DI & 76 & $17.1 \%$ \\
\hline NCAA DII & 33 & $7.4 \%$ \\
\hline NCAA DIII & 47 & $19.6 \%$ \\
\hline Secondary School & 219 & $49.3 \%$ \\
\hline
\end{tabular}

Table 2. Demographic and clinical practice information of the participants

\section{Screening Tool Usage}

Overall, the most commonly used screening tools were Strength $(342,91.9 \%)$, ROM $(339,91.1 \%)$, and History $(315,84.7 \%)$. The least commonly used screening tools were $D / J$ Land $(132,36.02 \%)$, MQual (212, 56.9\%), S/D Hop (233, 62.6\%), and Balance $(238,63.9 \%)$. A total of 18 participants $(4.8 \%)$ indicated that they do not use screening tools. Furthermore, 0-1 tool categories were used by 22 participants (5.9\%), 2-3 by 40 (10.8\%), 4-5 by $168(45.2 \%)$, and $6-7$ by $142(38.2 \%)$.

\section{Implementation Timing}

Frequencies related to implementation timing for each screening tool can be found in Figures 1-7 (ROM, Balance, Strength, D/J Land, S/D Hop, MQual, and History respectively). ROM, Strength, Balance, $D / J$ Land, $S / D$ Hop, and MQual were most frequently used post-injury as $61.6-83.2 \%$ of individuals indicated that they always or almost always complete these measures at that time. Additionally, participants indicated these measures were never or almost never used at the time of entry to the institution (56.5-70.1\%), preseason (54.0-69.4\%), in-season (52.7-67.6\%), and post-season (62.5-78.1\%). Injury history, however, was used always or almost always amongst (54.3\%) the participants at time of entry to institution indicating that it was the most used screening tool at this time.



Figure 1. Percentages of individuals that indicated frequency of use of ROM screening tools during various time points to assess injury risk. 


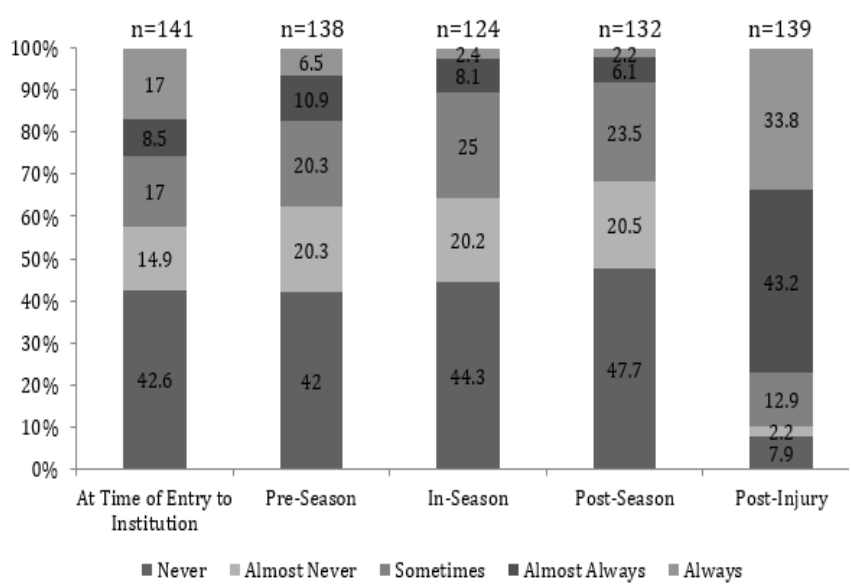

Figure 2. Percentages of individuals that indicated frequency of use of Balance screenin tools during various time points to assess injury risk.

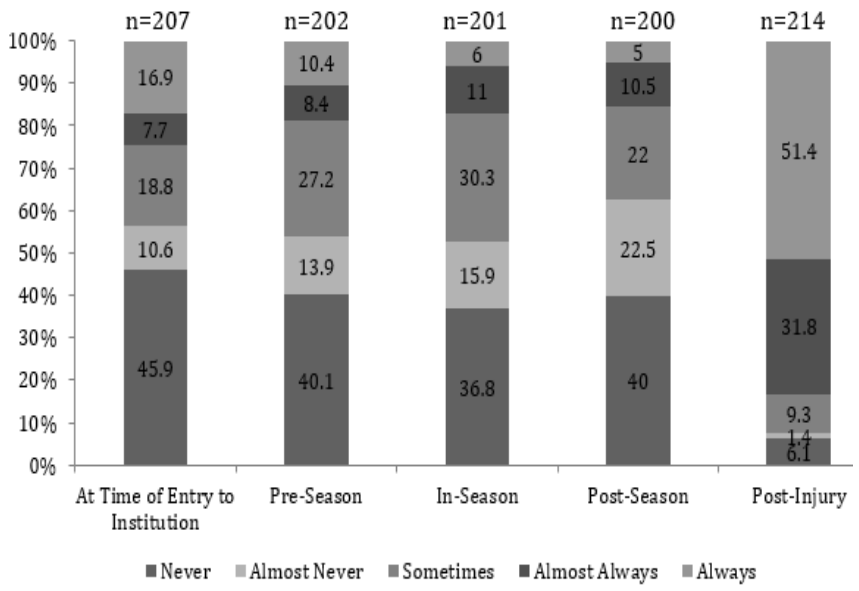

Figure 3. Percentages of individuals that indicated frequency of use of Strength screeni tools during various time points to assess injury risk.

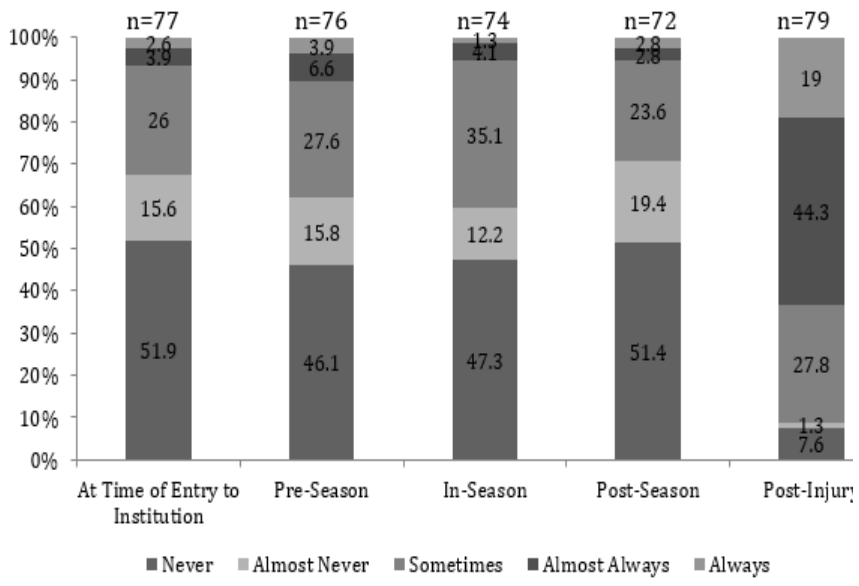

Figure 4. Percentages of individuals that indicated frequency of use of $D / J$ Landing screening tools during various time points to assess injury risk.

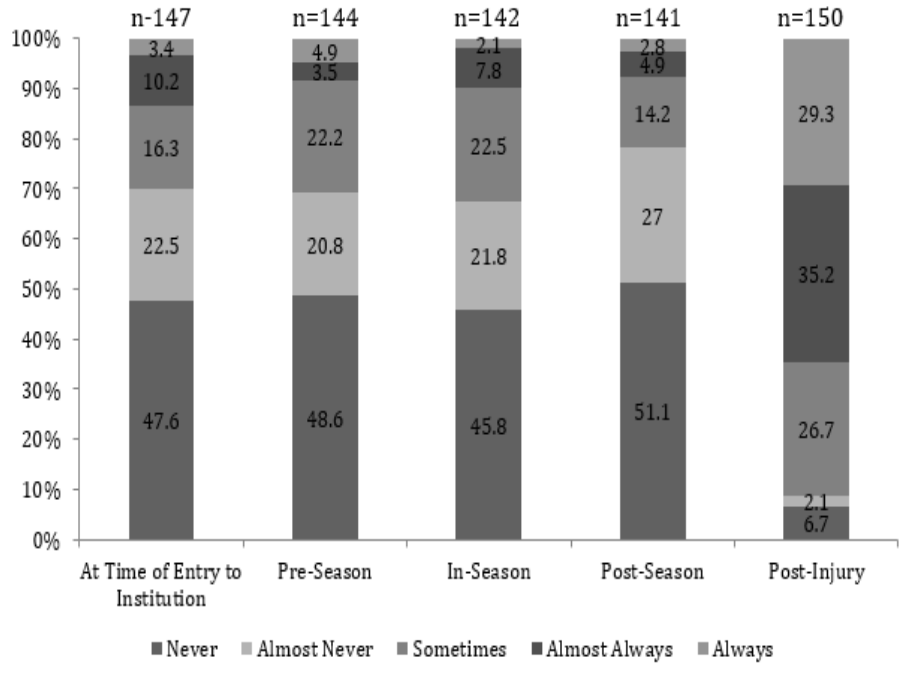

Figure 5. Percentages of individuals that indicated frequency of use of $S / D$ Hopping screening tools during various time points to assess injury risk.



Figure 6. Percentages of individuals that indicated frequency of use of MQual screening tools during various time points to assess injury risk. 


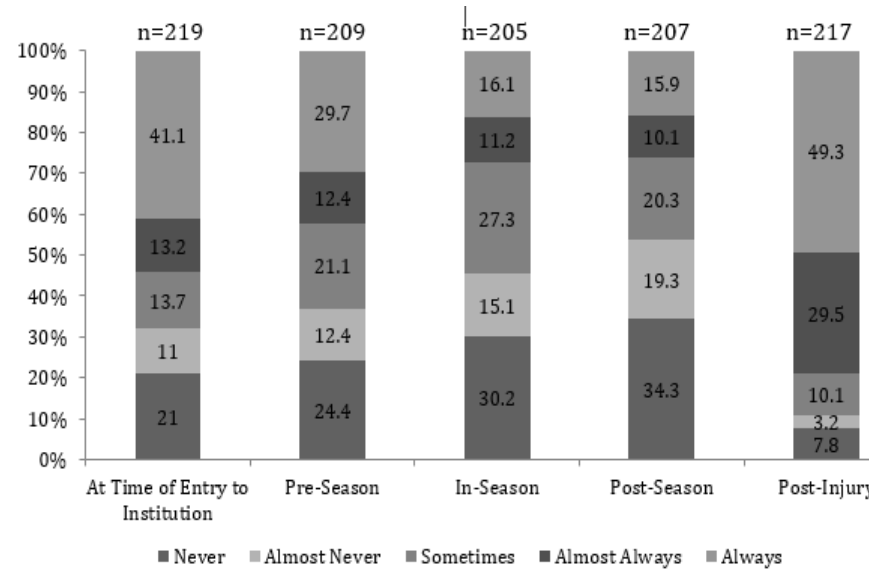

Figure 7. Percentages of individuals that indicated frequency of use of History screeni tools during various time points to assess injury risk.

\section{Return-to-Play Decisions}

Refer to Figures 8 and 9 for RTP information. Strength $(\mathrm{n}=222,87.4 \%)$, ROM $(\mathrm{n}=226,81.4 \%)$, and Balance $(\mathrm{n}=156,70.5 \%)$ had the highest numbers of individuals report that they were used always or almost always when making RTP decisions. $D / J$ Land $(\mathrm{n}=84,59.5 \%), S / D$ Hop ( $\mathrm{n}=157,64.4 \%)$, MQual ( $\mathrm{n}=137,61.3 \%)$, and History $(\mathrm{n}=225,56.9 \%)$ were used less frequently always or almost always of the time. Strength (72.3\%), ROM (62\%), and S/D Hop (67.6\%) had the highest levels of individuals indicating that they were very and extremely effective at providing information to make RTP decisions. Balance (57\%), D/J Land (55.2\%), MQual (50.7\%), and History (40.9\%) had lower levels of individuals indicating these screening tools provided very and extremely effective information regarding making RTP decisions.

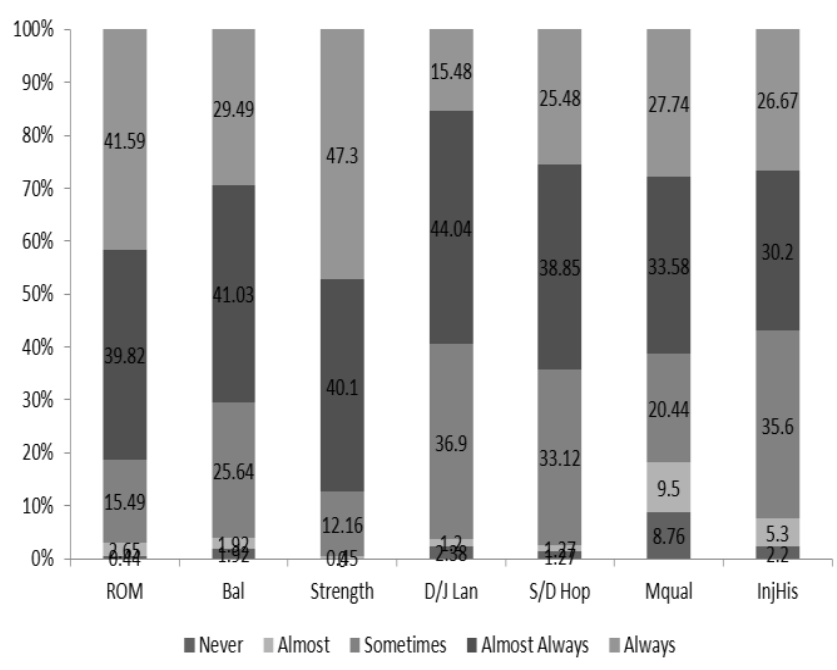

Figure 8. Frequency of use of screening tool for RTP decisions.

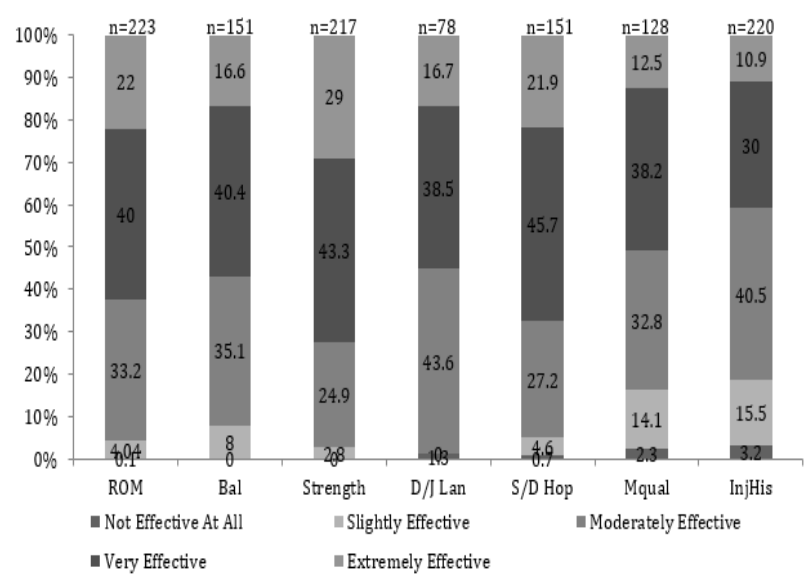

Figure 9. Perceived effectiveness of each screening tool for RTP decisions.

\section{Intervention Prescription}

Please refer to Table 3 for frequencies and percentages of program prescription based on category of screening tool used. Prophylactic bracing was the least commonly used intervention resulting from use of each screening tool (6.0$21.8 \%$ ). There were consistencies with the interventions prescribed matching the screening tool. For example, the most common intervention prescription for ROM screening tools was a stretching/ROM program (55\%), Balance screening tools prescribed balance training intervention (53.4\%), and Strength screening tools prescribed core and LE strengthening programs (63.4\% and 51.9\%). For all other categories and remainder of movement-based screening tools, the results revealed a generic prescription (27.7-51.5\%), suggesting the same series of interventions will be prescribed regardless of screening tool used. History had elevated measures for all intervention categories, ranging from $21.8 \%$ (prophylactic bracing) to $52.2 \%$ (stretching/ROM).

\section{DISCUSSION}

The purpose of this study was to explore LE MSK screening tool use among athletic trainers in traditional settings. Overall, the most commonly used MSK screening tools were ROM, Strength, and History. Additionally, the timing of use varied, with History most commonly used at time of entry to institution, and the functional based screening tools more widely used post-injury. MQual and $D / J$ Land were found to be the least commonly used tools, as well as had the lowest frequency of use for RTP decision-making. Additionally, there was little variation in intervention prescription based on specific MSK screening tool findings. This 
suggests that a generic intervention care plan is primarily prescribed regardless of results from each MSK screening tool.

Specifically concerning injury risk information, the results of this study demonstrated that ROM, Strength, and History screening tools were the most commonly used among traditional setting athletic trainers. While the literature suggests these screening tools provide relevant information, there is a lack of evidence to suggest they are superior at providing the most applicable information when it comes to injury risk. $8,15,19 \mathrm{~A}$ collection of tools may be needed to get a complete picture of injury risk during high functioning activities, as is required by athletic movements. ${ }^{19}$ Furthermore, it has been suggested that dynamic movement testing may provide highly relevant information for high functioning performance, and has been suggested as one of the most important components in athletic activity. $3,19,20$ Concerning those at risk for an anterior cruciate ligament tear, risk factors are specifically detected during jump landing. ${ }^{20}$ As such, the benefit of utilizing a dynamic leap and balance test over the use of the star excursion balance test has been demonstrated based on their ability to more closely mimic that of athletic participation. ${ }^{19}$ Our findings indicate that athletic trainers in traditional settings, however, are using these highly relevant screening tools $(D / J$ Land, MQual, $S / D$ Hop, and Balance) the least. Thus, there is a need to enhance the use of these screening tools in athletic trainers, to provide them with the best information to make intervention decisions related to reducing injury risk.

There are three levels of prevention: primary (before health effects/injury occur), secondary (screening to identify illnesses/injuries at earliest stages, before symptoms), and tertiary (managing disabling effects post-injury). ${ }^{21}$ Our findings indicate there was an overall lack of use of functional screening tool use prior to injury as most screening tools were reported as being used primarily after injury. We can infer from these results that the majority of preventative screening that is taking place is to inform secondary and tertiary prevention rather than primary. Once an injury occurs there are lasting effects from the injury, such as recurrence of injury, prolonged symptoms, and an increased risk of post-traumatic osteoarthritis. ${ }^{1,22}$ As mentioned earlier, those that suffer an ankle sprain have a $70 \%$ chance of sustaining of recurrent ankle sprains. ${ }^{2}$ This emphasizes the greater need for primary prevention to reduce this injury cycle from beginning altogether. This is not just specific to ankle injuries as those that have had a previous anterior cruciate ligament tear are more likely to suffer from another anterior cruciate ligament tear. ${ }^{23}$ While providing tertiary prevention will help to decrease the impact of the injury cycle, the literature suggest that mitigating the short- and long-term disability after an injury occurs is extremely difficult.2,3,20 Thus, it is important for athletic trainers to work to reduce the risk of first time injury in an effort to keep patients from ever entering this cycle of injury or at least in attempt to decrease the severity of risk in the first place.

Our results indicated a lack of variation of intervention prescriptions based on screening tools use. This was evident by limited variation in the frequency of specific prevention/rehabilitation categories being implemented based on specific injury screening tool results (Table 3). For example, stretching, balance, and strengthening programs all hovered around an implementation level of $45 \%$ regardless of screening tool used. This could suggest that blanket intervention programs are being used by athletic trainers regardless of what the results of the screening tools suggest as weaknesses or dysfunctional patterns of movement of an individual. There are several paradigms proposed for intervention prescription that ensure a patient-centered approach is taken, specifically, they point to the superiority of treating the specific impairments of the patient based on interventions designed to address those impairments. ${ }^{24,25}$ By implementing interventions that are specific to the individual and their impairments, clinicians can help mitigate the unique injury risk factors possessed by the patient. 24,25 Furthermore, injury risk is not determined by a single personal factor. Thus, injury risk should be determined based on multiple screening tools and specific interventions should be implemented that are tailored to the findings from the screening tools. 


\begin{tabular}{|c|c|c|c|c|c|c|c|}
\hline & $\begin{array}{l}\text { Balance } \\
\text { Training }\end{array}$ & $\begin{array}{l}\text { Core } \\
\text { Strengthening }\end{array}$ & $\begin{array}{l}\text { Prophylactic } \\
\text { Bracing }\end{array}$ & $\begin{array}{l}\text { Stretching } \\
\text { ROM }\end{array}$ & LE Strengthening & $\begin{array}{l}\text { Coordination/ } \\
\text { Movement } \\
\text { Pattern }\end{array}$ & $\begin{array}{l}\text { Neuromuscular } \\
\text { Control } \\
\text { Proprioception }\end{array}$ \\
\hline $\begin{array}{l}R O M \\
339\end{array}$ & $\begin{array}{l}113 \\
(33.3 \%)\end{array}$ & $\begin{array}{l}114 \\
(33.6 \%)\end{array}$ & $\begin{array}{l}30 \\
(8.8 \%)\end{array}$ & $\begin{array}{l}187 \\
(55 \%)\end{array}$ & $\begin{array}{l}137 \\
(40 \%)\end{array}$ & $\begin{array}{l}98 \\
(28.9 \%)\end{array}$ & $\begin{array}{l}94 \\
(27.7 \%)\end{array}$ \\
\hline $\begin{array}{l}\text { Balance } \\
238\end{array}$ & $\begin{array}{l}127 \\
(53.4 \%)\end{array}$ & $\begin{array}{l}97 \\
(41 \%)\end{array}$ & $\begin{array}{l}18 \\
7.5 \%)\end{array}$ & $\begin{array}{l}71 \\
(29.8 \%)\end{array}$ & $\begin{array}{l}89 \\
(37.3 \%)\end{array}$ & $\begin{array}{l}84 \\
(35.3 \%)\end{array}$ & $\begin{array}{l}88 \\
(37 \%)\end{array}$ \\
\hline $\begin{array}{l}\text { Strength } \\
343\end{array}$ & $\begin{array}{l}125 \\
(36.4 \%)\end{array}$ & $\begin{array}{l}151 \\
(63.4 \%)\end{array}$ & $\begin{array}{l}27 \\
(7.9 \%)\end{array}$ & $\begin{array}{l}134 \\
(39 \%)\end{array}$ & $\begin{array}{l}178 \\
(51.9 \%)\end{array}$ & $\begin{array}{l}105 \\
(30.6 \%)\end{array}$ & $\begin{array}{l}108 \\
(31.5 \%)\end{array}$ \\
\hline $\begin{array}{l}\text { D/J Land } \\
134\end{array}$ & $\begin{array}{l}47 \\
(35 \%)\end{array}$ & $\begin{array}{l}50 \\
(37.3 \%)\end{array}$ & $\begin{array}{l}8 \\
(6 \%)\end{array}$ & $\begin{array}{l}47 \\
(35 \%)\end{array}$ & $\begin{array}{l}61 \\
(45.5 \%)\end{array}$ & $\begin{array}{l}49 \\
(36.5 \%)\end{array}$ & $\begin{array}{l}54 \\
(40.2 \%)\end{array}$ \\
\hline $\begin{array}{l}S / D \text { Hop } \\
233\end{array}$ & $\begin{array}{l}113 \\
(48.5 \%)\end{array}$ & $\begin{array}{l}80 \\
(43.3 \%)\end{array}$ & $\begin{array}{l}22 \\
(9.4 \%)\end{array}$ & $\begin{array}{l}80 \\
(34.3 \%)\end{array}$ & $\begin{array}{l}120 \\
(51.5 \%)\end{array}$ & $\begin{array}{l}93 \\
(39.9 \%)\end{array}$ & $\begin{array}{l}98 \\
(42 \%)\end{array}$ \\
\hline $\begin{array}{l}\text { MQual } \\
212\end{array}$ & $\begin{array}{l}84 \\
(39.6 \%)\end{array}$ & $\begin{array}{l}83 \\
(39.1 \%)\end{array}$ & $\begin{array}{l}23 \\
(10.8 \%)\end{array}$ & $\begin{array}{l}95 \\
(44.8 \%)\end{array}$ & $\begin{array}{l}97 \\
(45.7 \%)\end{array}$ & $\begin{array}{l}82 \\
(38.7 \%)\end{array}$ & $\begin{array}{l}71 \\
(33.5 \%)\end{array}$ \\
\hline $\begin{array}{l}\text { History } \\
316\end{array}$ & $\begin{array}{l}144 \\
(45.6 \%)\end{array}$ & $\begin{array}{l}135 \\
(42.7 \%)\end{array}$ & $\begin{array}{l}69 \\
(21.8 \%)\end{array}$ & $\begin{array}{l}165 \\
(52.2 \%)\end{array}$ & $\begin{array}{l}171 \\
(54.1 \%)\end{array}$ & $\begin{array}{l}125 \\
(39.6 \%)\end{array}$ & $\begin{array}{l}128 \\
(40.5 \%)\end{array}$ \\
\hline
\end{tabular}

Table 3. Frequencies and Percentages of Programs Prescription Based on Category of Screening Tools Used

This study is not without limitations. The response rate of participants was low $(\sim 7.5 \%)$ in this study, and the participants that did choose to participate were primarily employed in the secondary school setting. This study was a retrospective, selfreported data, which introduce some inaccuracies and may not directly reflect actual practices and procedures completed in clinical practice. Also, the research team can only speculate what prevention practices athletic trainers implemented based on MSK screening tool usage since actual and specific injury prevention practices were not evaluated. Future research should investigate athletic trainers' primary injury preventative practices across all settings and focus on objectively measuring MSK screening tool usage in a prospective fashion. Additionally, research should be done to articulate reasoning behind screening tool use, and didactic reasoning concerning intervention prescriptions.

\section{CONCLUSION}

The use of MSK screening tools to provide the most relevant injury risk information and subsequent intervention prescription among athletic trainers in traditional settings is a strike contrast to what literature suggests as a patientcentered approach. There are multiple ways athletic trainers in this study demonstrate this gap. First, there is a lack of use of $D / J$ Land and MQual screening tools to provide the most relevant information regarding functional movement injury risk. Secondly, prevention practices are leaning towards tertiary prevention rather than primary prevention practices, based on the timing of screening tool use. Finally, there is a lack of variation in intervention prescription to match specific findings from screening tools. This suggests athletic trainers may be using blanket intervention prescription rather than impairment-based intervention programs.

\section{ACKONWLEDGMENT}

This research was supported financially by the Indiana State University Graduate Student Research Grant.

\section{REFERENCES}

1. Kaminski TW, Hertel J, Amendola N, et al. National Athletic Trainers' Association position statement: Conservative management and prevention of ankle sprains in athletes. J Athl Train. 2013;48(4):528-545. 
2. Hertel J. Functional instability following lateral ankle sprain. Sports Med. 2000;29(5):361-371.

3. Wikstrom EA, Tillman MD, Chmielewski TL, Cauraugh JH, Borsa PA. Dynamic postural stability deficits in subjects with selfreported ankle instability. Med Sci Sports Exerc. 2007;39(3):397-402.

4. Bahr $R$, Holme I. Risk factors for sports injuries-- $A$ methodological approach. Br J Sports Med. 2003;37(5):384392.

5. Waterman BR, Owens BD, Davey S, Zacchilli MA, Belmont PJ, Jr. The epidemiology of ankle sprains in the United States. J Bone Joint Surg Am. 2010;92(13):2279-2284.

6. Finch CF. No longer lost in translation: The art and science of sports injury prevention implementation research. Br J Sports Med. 2011;45(16):1253-1257.

7. Dallinga JM BA, Lemmink KAPM. Which screening tools can predict injury to the lower extremities in team sports? Sports Med. 2012;42(9):791-815.

8. Fox AS, Bonacci J, McLean SG, Saunders N. Efficacy of ACL injury risk screening methods in identifying high-risk landing patterns during a sport-specific task. Scand J Med Sci Sports. 2017;27(5):525-534.

9. Hegedus EJ, McDonough S, Bleakley C, et al. Physical performance tests predict injury in National Collegiate Athletic Association athletes: A three-season prospective cohort study. Br J Sports Med. 2016;50(21):1333-1337.

10. Lam KC, Valier AR, Anderson BE, McLeod TC. Athletic Training services during daily patient encounters: A report from the Athletic Training Practice-Based Research Network. J Athl Train. 2016;51(6):435-441.

11. Vriend I, Gouttebarge V, Finch $C F$, van Mechelen $W$, Verhagen E. Intervention strategies used in sport injury prevention studies: A systematic review identifying studies applying the haddon matrix. Sports Med. 2017;47(10):2027-2043.

12. Saragiotto BT, Di Pierro C, Lopes AD. Risk factors and injury prevention in elite athletes: A descriptive study of the opinions of physical therapists, doctors and trainers. Braz J Phys Ther. 2014;18(2):137-143.

13. Klugl M, Shrier I, McBain K, et al. The prevention of sport injury: An analysis of 12000 published manuscripts. Clin J Sport Med. 2010;20(6):407-412.

14. Rivera MJ, Winkelmann ZK, Powden CJ, Games KE. Proprioceptive training for the prevention of ankle sprains: An evidence-based review. J Athl Train. 2017;52(11):1065-1067.
15. Gabbe BJ BK, Wajswelner H, Finch C. Reliability of common lower extremity musculoskeletal screening tests. Physl Ther Sport. 2004;5(2):90-97.

16. Wright AA, Dischiavi SL, Smoliga JM, Taylor JB, Hegedus EJ. Association of Lower Quarter Y-Balance Test with lower extremity injury in NCAA Division 1 athletes: An independent validation study. Physiotherapy. 2017;103(2):231-236.

17. Clifton DR, Grooms DR, Hertel J, Onate JA. Predicting injury: Challenges in prospective injury risk factor identification. J Athl Train. 2016;51(8):658-661.

18. Sefton JM, Lohse KR, McAdam JS. Prediction of injuries and injury types in army basic training, infantry, armor, and cavalry trainees using a common fitness screen. J Athl Train. 2016;51(11):849-857.

19. Jaffri AH, Newman TM, Smith BI, John Miller S. The Dynamic Leap and Balance Test (Dlbt): A test-retest reliability study. Int J Sports Phys Ther. 2017;12(4):512-519.

20. Hewett TE, Myer GD, Ford KR, Paterno MV, Quatman CE. Mechanisms, prediction, and prevention of ACL injuries: Cut risk with three sharpened and validated tools. J Orthop Res. 2016;34(11):1843-1855.

21. Picture of America Prevention. Centers for Disease Control and Prevention. Picture of America Web site. https://www.cdc.gov/pictureofamerica/pdfs/picture_of_amer ica_prevention.pdf. Accessed.

22. Gribble PA, Bleakley CM, Caulfield BM, et al. 2016 consensus statement of the International Ankle Consortium: Prevalence, impact and long-term consequences of lateral ankle sprains. $\mathrm{Br}$ J Sports Med. 2016;50(24):1493-1495.

23. Gans I, Retzky JS, Jones LC, Tanaka MJ. Epidemiology of recurrent anterior cruciate ligament injuries in National Collegiate Athletic Association Sports: The Injury Surveillance Program, 2004-2014. Orthop J Sports Med. 2018;6(6):2325967118777823.

24. Donovan L, Hart JM, Saliba SA, et al. Rehabilitation for chronic ankle instability with or without destabilization devices: A randomized controlled trial. J Athl Train. 2016;51(3):233-251.

25. Donovan L, Hertel J. A new paradigm for rehabilitation of patients with chronic ankle instability. Phys Sportsmed. 2012;40(4):41-51. 